\title{
A Naturalização nos Estados Hispano-Americanos do Mercosul
}

\section{Florisbal de Souza Del'Olmo'}

É objetivo do presente trabalho tecer considerações sobre o instituto da naturalização nos Estados de fala espanhola do Mercado Comum do Sul, Mercosul, quais sejam, a Argentina, o Paraguai e o Utuguai.

\section{Considerações iniciais}

Entende-se naturalização como o ato pelo qual o estrangeiro ou o anacional (indivíduo não-detentor da prerrogativa fundamental da nacionalidade por qualquer Estado, conhecido também por apátrida) se investe juridicamente da condição de nacional do país que adota. No caso do estrangeiro implica rotineiramente a renúncia de sua nacionalidade de origem. Trata-se de nacionalidade derivada, uma vez que adquirida após o nascimento.

O termo naturalização está consagrado. Tem, em verdade, o significado de nacionalização, palavra que mellıor identificaria o procedimento que designa, conforme observam VALLADÃO $O^{2}$ e $B O G G I A N O^{3}$, mas que não costuma ser utilizada com relação a seres humanos, pessoas naturais, pessoas físicas, empregando-se, isto sim, para pessoas jurídicas.

\footnotetext{
1 autor é Mestre em Direito (Relações Internacionais) pela UFSC/URI. É professor de Direito Internacional Privado e Direito Internacional Público, na Universidade Regional Integrada do Alto Uruguai e das Missooes, URI, campus de Santo Ângelo, RS, e do Instituto de Ensino Superior de Santo Ângelo, TESA, na mesma cidade. Escreveu Direito Internacional Privado - Abordagens Fundamentais, Legisłação, Jurisprudência, em 1999, e O Mercosul e a Nacionalidade: Estudo à Luz do direito Internacional (no prelo), ambos pela Editora Forense, do Rio de Janeiro.

${ }^{2}$ VALLADÃO, Haroldo. Direito internacional privado, p. 287.

${ }^{3}$ BOGGIANO, Antonio. La doble nacionalidad en derecho internacional privado, p. 60-66. Convém acentuar que esse autor emprega o termo nacionalização (nacionalización, no original) em sua obra, ao invés de naturalização.
} 
$L A P R A D E L L E$ já lembrou que, enquanto a nacionalidade originária depende de vontade do Estado, a naturalização "depende da vontade do homem: a primeita é uma nacionalidade de atríbuição, a segunda uma nacionalidade de eleição"4.

Essa vontade do indivíduo é tão ponderável que caracteriza o ocaso da aligeância, também denominada vassalagem ou subordinação perpétua, pela qual o homem só podia adquirir uma nova nacionalidade se o seu Estado de origem o permitisse, segundo constata $A R A U U^{\prime} O^{5}$.

Pode-se adiantar que a tendência atual é concedcrem-se ao naturalizado todos os direitos e obrigações atribuídos ao nacional originário do Estado, sem discriminação. Lamenta $A C C I O L Y$ existirem, contudo, legislações que "negam aos naturalizados certos privilégios de que gozam os nacionais de origem. Assim, em muitos países, não se lhes reconhecem todos os direitos políticos ou não se thes permite o exercício de certas funções públicas".

Ao abordar-se, sucintamente, a naturalização no ordenamento jurídico dos três Estados hispano-americanos do Mercosul, verifica-se que o instituto está presente em apenas dois deles, já que o ordenamento jurídico uruguaio não o recepciona.

\section{Argentina}

$\mathrm{O}$ artigo 20 , em sua última parte, da vigente Constituição, de $1^{\circ}$ de maio de 1853, concede a naturalização a quem complete dois anos consecutivos de residência na Argentina. Textualmente: "Obtêm a naturalização tesidindo dois anos contínuos na Nação; mas a autoridade pode diminuir este prazo em favor de quem o solicite, alegando e provando serviços à República".

Em um único artigo da norma jurídica ordinária encontramse a essência da legislação argentina sobre a nacionalidade derivada. Trata-se do artígo $2^{\circ}$, da repristinada Lei $n^{\circ} 346$, de 8 de outubro de 1869 , pelo qual são argentinos naturalizados: "Art. $2^{\circ}-1^{\circ}-$ Os estrangeiros maiores de dezoito anos, que residam na República dois anos consecutivos e manifestem perante os juízes federais da seção sua vontade de sê-lo. $2^{\circ}$ - Os estrangeiros que comprovem perante ditos juízes haver prestado, qualquer que seja o tempo de sua residência, algum dos seguintes serviços: 1) ter desempenhado com dignidade trabalho em favor da Nação ou das províncias, dentro ou fora da República; 2) ter servido no exército ou na marinha, ou haver participado

\footnotetext{
4 $\Lambda$ KZIN, MM. B. et al. La nacionalité dans la science sociale et dans le droit contemporain, p. 209. Tradução do original pelo autor.

5 ARAÚJO, Luis Yvani de Amorim. Curso de direito internacional público, p 70.

- ACCIOLY, Hildebrando e SILVA, Geraldo Eulálio do Nascimento e. Manual de direito internacional público, p. 325.
} 
de uma ação de guerra em defesa da Nação; 3) ter estabelecido no país uma nova indústria ou introduzido uma invenção útil; 4) ser empresário ou construtor de ferrovias em qualquer das províncias; 5) estar tomando parte nas colônias agrícolas estabelecidas ou que venham a estabelecer-se em territórios nacionais ou nos das províncias, contanto que possuam nelas alguma propriedade imóvel; 6) habitar ou povoar territórios nacionais nas linhas atuais de fronteira ou fora delas; 7) ter casado com mulher argentina em qualquer das províncias; 8) exercer nelas o magistério em qualquer dos ramos da educação ou da cultura"7.

Como se observa, ao contrário da maioria dos ordenamentos jurídicos, o argentino considera a naturalização um direito, reconhecido ao estrangeiro que resida no país por dois anos consecutivos, conforme a expressa dicção do artigo mencionado da Lei $\mathrm{n}^{\circ} 346$, de 8 de outubro de 1869, o qual disciplina o dispositivo da Carta Magna sobre o instituto. Essa, em seu artigo 20, parte final, permite, ainda, a diminuição desse prazo, pela autoridade competente, em favor de quem haja prestado determinados serviços ao Estado.

E esses serviços estão identificados no texto legal ordinário, antes mencionado. Não se trata de uma pretrogativa outorgável ao alvedrio da autoridade concedente, mas de um direito invocável pelo estrangeiro que preencha os tequisitos legais.

Assim, são oportunas as palavras de $S A B S A Y$, para quem "a aquisição da nacionalidade argentina está regulada como um direito para o esrrangeiro que habita o pás e não como uma obrigação". O requerente, adimplidos os pressupostos legais, fará jus ao status de argentino, mediante o instituto da naturalização.

Enfatizando as colocações feitas, observa-se que o texto constitucional afirma "obtêm a naturalização", de forma clara, não autorizando a imposição, pela autoridade, de quaisquer condicionantes, além dos pressupostos legais mencionados.

Uma particularidade - da mais alta importância neste breve estudo - do ordenamento jurídico argentino é o fato de a naturalização ser concedida pelo Poder Judiciário. Isso porque, como se observa nas legislações da maioria expressiva dos demais países, a concessão da naturalização é prerrogativa do Poder Executivo.

$O$ artigo $5^{\circ}$ do Decreto $n^{\circ} 3.213$, de 28 de setembro de 1984 , que regulamenta a Lei ${ }^{\circ} 23.059$, de 6 de abril de 1984 , estabelece, em sua primeira parte, que "o estrangeiro que deseje naturalizat-se argentino deverá apresentat-se perante o juiz federal competenre em seu domicílio"".

Após prescrever a documentação regulamentar a ser apresentada pelo candidato à

\footnotetext{
7 ZAVALIA, Ricardo de. Constitución de la nación argentina, p. 297-298.

\& SABSAY, Daniel Alberto e ONAINDIA, José Miguel. La Contitución de los argentinos, p. 73.

${ }^{9}$ Constitución de la Nación Argentina - Editorial Universidad, p. 170.
} 
naturalização, a Constituição argentina, ainda no artigo $5^{\circ}$, e também no artigo $6^{\circ}$, esse último em sua parte final, estabelece: "Com seu adimplemento, os juízes despacharão, outorgando ou denegando o pedido, considerados os elementos de juízo constantes dos autos, no prazo de 90 dias".

\section{Uruguai}

A República Oriental do Uruguai, ao contrário dos outros ordenamentos jurídicos em estudo, não alberga a naturalização, constituindo-se em marcante exceção, quando considerado o conjunto dos Estados que formam a sociedade internacional.

Instituto com certa semelhança à naturalização é o oferecido ao estrangeiro com residência, negócio ou propriedade no Uruguai: o da cidadania legal. Isso poderia levar o pesquisador menos percuciente a pensar tratar-se de naturalização. É que o Estado Oriental é bastante peculiar nesse tema.

JIMENEZ DE ARECHAGA, após recordar a subordinação da qualidade de cidadão à condição de nacional na quase unanimidade dos ordenamentos jurídicos do mundo, afirma: "Este é o conceito dominante em quase todos os países, do qual se afasta em vários aspectos o nosso regime constitucional na matéria, que é nesse problema de uma heterodoxia singular. Em nosso pais se pode ser cidadão sem ser nacional. O cidadão legal, que $\mathrm{em}$ outros países se chama naruralizado, tem o direito de cidadania, pode votar e ser eleito, mas não é nacional do país. Ou seja, é um cidadão, sem ser nacional. A aquisição da cidadania só confere direitos políticos, mas não atribui a qualidade de nacional. O estrangeiro cidadanizado continua sendo estrangeiro"10".

\section{Paraguai}

A Constituição da República do Paraguai, de 20 de junho de 1992, prescreve, em seu artigo 147, os casos de naturalização. $O$ estrangeiro interessado em adquirir a nacionalidade paraguaia deverá preencher os seguintes requisitos: "majoridade, residência mínima de três anos no território paraguaio, exercício regular de alguma profissão, arte, ocupação, aptidão ou perícia, e boa conduta definida em lei" "11.

"6IMENEZ DE ARECHAGA, Eduardo et al. Derecho internacional público, p. 16.

"LA NUEVA Constitución Nacional, p. 27. 
Para requerer a naturalização na República do Paraguai o estrangeiro deverá comprovar o atendimento cumulativo de diversos requisitos.

O primeiro requisito é a maioridade. Não esclarece o constituinte se essa maioridade é pela legislação paraguaia ou pela do país do adventício. Entende-se que deva ser a lei paraguaia, sendo necessário, então, que o estrangeiro tenha completado dezoito anos, idade preconizada no estatuto maior paraguaio (artigo 151 , inciso $1^{\circ}$ ), para o pleno exercício da cidadania.

Deverá o candidato à naturalização comprovar estar residindo no Paraguai há três anos. O termo vernáculo empregado pelo constituinte foi radicación. Ora, essa palavra - ou sua correspondente em português, radicação - significa ação ou efeito de radicar. E radicar é estar em determinado lugar ${ }^{12}$. Em português é definida também como fixar definitivamente residência ${ }^{13}$. De qualquer modo, o que se está procurando demonstrar é que a intenção do legislador maior paraguaio é exigir a residência do candidato à naturalização no Paraguai e não o simples domicílio do mesmo. Por conseguinte, basta a residência no território paraguaio pelo tempo prescriro, três anos, para o estrangeiro satisfazer o requisito do inciso $2^{\circ}$ do artigo 147 da Constituição paraguaia.

Outra exigência é o exercício regular, no país, de uma profissão, arte ou perícia em alguma atividade laboral. Ou seja, o constituinte não admitia que o estrangeito viesse a tornar-se paraguaio sem aptidão para prover sua própria manutenção e a de seus dependentes. Há necessidade de que ele aufira, por seus próprios meios, trabalho ou ocupação profissional, rendimentos mínimos capazes de não expô-lo a buscar de terceiros ou da caridade pública a própria sobrevivência e a de seus familiares.

Finalmente, requer-se boa conduta do naturalizando, deixando a lei máxima ao legislador comum a tatefa de definir o que seja boa conduta, pois a referida expressão é de imprecisão absoluta. Contudo, por certo, serão admiridas como aptas, e isso se comprova normalmente através de certidão ou atestado de qualquer autoridade administrativa, as pessoas que possuam os requisitos mínimos de convivência social, não preenchendo esses pressupostos aqueles indivíduos notoriamente portadores de atributos negativos penais, como delinqüentes comuns, traficantes, entre outros.

¿2 DICCIONARIO de la lengua española, p. 784.

${ }^{13}$ MICHAELIS: moderno dicionário da lingua portuguesa, P. 1762. 


\section{Considerações finais}

Como se depreende, o instituto da naturalização se encontra regulado de maneita distinta nos três Estados hispano-americanos do Mercosul. Não há, contudo, como se observa do estudo, manifesta indisposição jurídica em relação ao estrangeiro, mesmo que assim se considere também aquele oriundo do bloco económico, o futuro cidadão comunitátio. A possibilidade de aproximação entre as legislações da espécie é não só viável como conveniente.

Residem na tegulamentação constitucional da naturalização discrepâncias legislativas entre os três países do bloco regional do Cone Sul, cada um deles com normas peculiares. O caso mais radical se encontra no ordenamento jurídico do Uruguai, que não acoberta o instituto da naturalização, com o que o estrangeiro jamais se verá investido da nacionalidade uruguaia.

No sentido oposto, com largo espaço para a naturalização, está a legislação argentina, segundo a qual a concessão é prerrogativa do Poder Judiciário, tendo o estrangeiro a postulação da nacionalidade como um diteito, sem ficar na dependência ou ao alvedrio do Executivo, como soe acontecer em quase todos os ordenamentos jurídicos. O periodo de residência na Argentina é de apenas dois anos, tempo que pode ainda ser diminúfo mediante cumprimento de outros pressupostos, como o casamento com mulher de nacionalidade argentina, o estabelecimento de alguma indústria no país ou o exercício do magistério em qualquer área da educação.

O Paraguai exige três anos de residência para o estrangeiro requerer a nacionalidade mediante naturalização, além de outros pressupostos, não diferentes, em tese, dos requisitos inseridos na legislação dos demais países e comuns no Direito Internacional. A dicção do texto constitucional guarani estabelece que os estrangeiros poderão obter a nacionalidade, com o que se entende que é uma prerrogativa da autoridade paraguaia concedê-la, não caracterizando um direito, como ocorre na legislação argentina.

A naruralização se apresenta como um instituto de grande importância nas relações intetnacionais nestes tempos de globalização. $\grave{A}$ proporção que mais pessoas se deslocam de sua pátria para outros países e aí se engajam em um projeto de vida e se integram na cultura e nos hábitos locais, a incorporação delas aos nacionais se torna cada vez mais desejável. Com muito mais razão isso se compreende quando se trata de um bloco econômico futuroso como o Mercosul. 


\section{REFERÊNCIAS BIBLIOGRÁFICASS}

ACCIOLY, Hildebrando e SILVA, Geraldo Eulálio do Nascimento e. Manual de direito internacional público. 12. ed. São Paulo: Saraiva, $1996.537 \mathrm{p}$.

AKZIN, Mm. B., ANCEL, M. et al. La nacionalité dans la science social et dans le droit contemporain. Paris: Librairie du Recueil Sirey, 1933. 349 p.

AMORIM, Edgar Carlos de. Direito internacional privado. 3. ed. Rio de Janeiro: Forense, 1995. 342 p.

ARAÚJO, Luis Ivani de Amorim. Curso de direito internacional público. 9. ed. Rio de Janeito: Forense, 1995. 364 p.

BOGGIANO, Antonio. La doble nacionalidad en derecho internacional privado. Buenos Aires: Depalma, 1973. $150 \mathrm{p}$.

CONSTITUCIÓN de la Nación Argentina. Buenos Aires: Editorial Universidad, 1985. $257 \mathrm{p}$.

DEL'OLMO, Florisbal de Souza. Direito internacional privado: abordagens fundamentais, legislação, jurisprudência. Rio de Janeiro: Forense, 1999.259 p.

DICCIONARIO de la lengua española. Madri: Espasa Calpe, 1995. 1021 p.

JIMENEZ DE ARECHAGA, Eduardo, VIGNALI, Heber Arbuet e RIPOLL, Roberto Puceiro. Derecho internacional público. v. I - IV. 2. ed. Montevidéu: Fundação de Cultura Universitária, 1996.

LA NUEVA Constitución Nacional. Assunção: Noticias El Diario rpc, 1992. $58 \mathrm{p}$.

MICHAELIS: moderno dicionário da língua portuguesa. São Paulo: Melhoramentos, 1998. 2259 p.

SABSAY, Daniel Alberto e ONAINDIA, José Miguel. La constitución de los argentinos. 4.ed. Buenos Aires: Errepar, 1998. 445 P.

VALLADÃO, Haroldo. Direito internacional privado. 5. ed. Rio de Janeiro: Freitas Bastos, 1980. v. I. 526 p.

ZAVAlíA, Ricardo de. Constitución de la Nación Argentina. Buenos Aires: Zavalía S. A., 1998.519 p. 